\title{
Localization of Connexin 26, 32 and 43 in Rat Parotid Glands
}

\author{
Chan Young Lee', Takashi Muramatsu ${ }^{1,2}$ and Masaki Shimono ${ }^{1,2}$ \\ 'Department of Pathology, 'Oral Health Science Center, Tokyo Dental College, 1-2-2, Masago, Mihama-ku, \\ Chiba, 261-8502
}

Received for publication March 10, 1998

\begin{abstract}
We investigated the distribution and localization of connexin 26,32 , and 43 in rat parotid glands. Immunofluorescence microscopy revealed the presence of spots reacting for connexin 26 and 32 between endpiece cells. A few spots indicating connexin $\mathbf{4 3}$ occasionally were observed in the parotid glands. Connexin 43-positive spots were localized around intercalated ducts. No positive spots for these connexins were detected between ductal cells. Double

that connexin 26-reactive sites could be observed within the same spots as connexin 32. Double immuno-electron microscopy confirmed that connexin 26 and 32 were co-localized in the same gap junction. These results suggest that connexin 26 and 32 are associated with secretory function and permeability between endpiece cells and that connexin 43 is associated with contraction of the myoepithelial cells that surround intercalated ducts in the rat parotid glands.
\end{abstract} immunofluorescence microscopy revealed

Key words: Connexin, Gap junction, Parotid gland, Acinar cell, Myoepithelial cell

\section{Introduction}

Gap junctions (GJs) are transmembrane sites that directly link adjacent cells and that mediate the intercellular movement of low molecular weight substances such as cAMP and $\mathrm{Ca}^{2+}$. Gap junctional intercellular communication is thought to play an important role in maintenance of homeostasis and coordination of secretion in multicellular organs [15]. GJs often are abundant in exocrine glands. It has been ultrastructurally confirmed that GJs are present between secretory cells in rat parotid (PGs) [6, 8], submandibular [5], and sublingual glands [18, 21, 22] as well as in bat PGs [24].

GJs are composed of connexon, which consist of protein assemblies referred to connexins (CXs). Many different CXs with varying degrees of sequence homology have been found. They are distinguished by reference to the CX molecular weight predicted from the corresponding cDNA [2, 3]. Recently, the distribution and localization of these CXs have been investigated in various organs by use of specific antibodies $[4,9,12,14,16,23,26]$. GJs between endpiece cells in exocrine glands consist of a $21 \mathrm{kDa}$ protein called connexin26 (CX26) [26] and a $27 \mathrm{kDa}$ protein called connexin 32 (CX32) $[9,12,20]$, while

Correspondence to: Takashi Muramatsu, D.D.S, Ph.D., Department of Pathology and Oral Health Science Center, Tokyo Dental College, 1-2-2, Masago, Mihama-ku, Chiba 261-8502, Japan. those in endocrine glands are composed of a $43 \mathrm{kDa}$ protein called connexin $43(C X 43)[2,3]$. However, there have been only a few reports of CXs expression in rat salivary glands $[10,13,16,17]$. Muramatsu et al. (1996) showed that CX32 was localized in GJs between endpiece cells and that CX43 was found between myoepithelial cells of rat submandibular and sublingual glands [17]. Hirono et al. (1995) demonstrated immunohistochemically the expression of CX26 and 32 between endpiece cells in rat PGs and that of CX26 in the intercalated duct [10]. However, this localization was not fully clarified at the immunocytochemical level. It is still an open question as to whether CX26 and 32 co-exist in the same GJ. Further, no report has documented the existence of CX43 in PGs, although myoepithelial cells are present on the intercalated duct in PGs [7].

The purpose of this study was to investigate the distribution and localization of CX26, 32 and 43 in rat PGs by means of immunohistochemistry and immunocytochemistry.

\section{Materials and Methods}

\section{Animals and tissue preparation}

PGs were obtained from 32 adult male SpragueDawley rats weighing about $300 \mathrm{~g}$ that were under deep anesthesia induced by sodium thiopenthal. After dissection, PGs were quickly frozen in liquid nitrogen and stored 
at $-80^{\circ} \mathrm{C}$ for immunohistochemical experiments. The immunocytochemical procedures were carried out according to Koike et al. (1993) [11]. Perfusion fixation with 1\% paraformaldehyde-0.1 $\mathrm{M}$ phosphate buffer (PB) was performed transcardially. The PGs samples were cut into small pieces and left in the same fixation for $5 \mathrm{hr}$.

\section{Antibodies}

Polyclonal antibody anti-CX26 (amino acid sequence 101-119) was kindly supplied by Prof. Y. Shibata and Dr. A. Kuraoka (Kyushu University, Fukuoka, Japan). The characteristics and specificity of this antibody have previously been demonstrated [14]. Mouse monoclonal antibody anti-CX32 (6-3G11) was supplied by the courtesy of Dr. F. Ueda (Nippon Shinyaku Co., Kyoto, Japan). This antibody binds to a cytoplasmic epitope, the carboxyl-terminal domain of CX32 [23]. Mouse monoclonal antibody anti-CX43 (amino acid sequence 252-270, Zymed Laboratories, San Francisco, CA) was used.

\section{Immunohistochemistry}

For immunohistochemistry, indirect immunofluorescence was performed on non-fixed cryosections according to the method of Muramatsu et al. (1996) [17] with modification. In brief, PGs were embedded into O.C.T. compound (Tissue Tek; Miles, Elkhart, IN) and quickly frozen in liquid nitrogen. They were sectioned at $6 \mu \mathrm{m}$ at $-20^{\circ} \mathrm{C}$, and were mounted on silane-coated glass slide. Non-specific binding was blocked with $10 \%$ goat or rabbit serum in $0.01 \mathrm{M}$ phosphate buffer saline (PBS) for $30 \mathrm{~min}$, and then the specimens were incubated with antiCX26 (diluted 1: 100 in PBS), anti-CX32 (diluted 1:1000 in PBS), or anti-CX43 (diluted $1: 1000$ in PBS) antibodies for $12 \mathrm{hr}$ at $4^{\circ} \mathrm{C}$. After rinsing in PBS for $15 \mathrm{~min}$, specimens were incubated with fluorescein isothiocyanate (FITC)-conjugated antibody (Cappel; Durham, NC) to mouse or rabbit IgG diluted 1:200 in PBS for $12 \mathrm{hr}$ at $4^{\circ} \mathrm{C}$. After washing, they were observed under a fluorescence microscope (Olympus BHT-RFK, Olympus, Tokyo, Japan).

Double immunofluorescent microscopy using both anti-CX32 and anti-CX26 antibodies was performed according to Kuraoka et al. (1993). After immunofluorescent staining with anti-CX32 and FITC-conjugated antibody as above, the same specimens were blocked with $10 \%$ goat serum in PBS for $30 \mathrm{~min}$ and incubated with anti-CX26 antibody for $24 \mathrm{hr}$ at $4^{\circ} \mathrm{C}$. After rinsing in PBS, specimens were incubated with rhodamine-conjugated goat anti-rabbit IgG (Tago; Burlingame, CA) diluted 1:50 in PBS for $24 \mathrm{hr}$ at $4^{\circ} \mathrm{C}$ and observed under a fluorescence microscope.

For quantitation, color slides at a magnification of $\times 100$ were projected onto a photographic screen. The number of fluorescent spots was scored. Data were expressed as the number of immunolabeled spots per 10,000 $\mu \mathrm{m}^{2}$ of tissue. The data comparing CX26 with 32, CX26 with 43 , and CX32 with 43 were analyzed statistically by
Mann-Whitney's U test. The criterion for statistical significance was $\mathrm{p}<0.01$.

\section{Immunocytochemistry}

For investigation of CX26 and 32 co-localization, the ultrathin cryosection method was utilized. Specimens were quickly frozen in liquid nitrogen after cryoprotection in 2.3 M sucrose- $0.1 \mathrm{M}$ PB for one day at $4^{\circ} \mathrm{C}$, then cut into $80 \mathrm{~nm}$-thick sections on a Reichert Ultracut-S equipped with an FC4E cryoattachment (Reichert, Vienna, Austria) at $-100^{\circ} \mathrm{C}$. The sections were mounted on 200 mesh nickel grids and rinsed in PBS for $2 \mathrm{hr}$ and then blocked for $30 \mathrm{~min}$ with PBS containing $0.1 \mathrm{M}$ glycine and $1 \%$ bovine serum albumin (PGB). They were incubated with anti-CX32 antibody for $12 \mathrm{hr}$ at $4^{\circ} \mathrm{C}$, washed in PBS for $2 \mathrm{hr}$ at room temperature, and then incubated for $12 \mathrm{hr}$ at $4^{\circ} \mathrm{C}$ with colloidal gold conjugated goat anti-mouse IgG (particle size : $5 \mathrm{~nm}$, Zymed) diluted 1:20 in PGB. After rinsing in PBS for $2 \mathrm{hr}$, they were incubated with anti-CX26 antibody for $12 \mathrm{hr}$ at $4^{\circ} \mathrm{C}$. After washing in PBS in $2 \mathrm{hr}$, they were incubated with colloidal gold conjugated goat anti-rabbit IgG (particle size : $10 \mathrm{~nm}$, Zymed) diluted $1: 20$ in PGB. The sections were post fixed in $1 \% \mathrm{OsO}_{4}$ $0.1 \mathrm{M} \mathrm{PB}$ for $1 \mathrm{hr}$ after washing in PBS. They were dehydrated, embedded in acrylic resin (LR White, The London Resin, Hampshire, NW, UK), and after staining with uranyl acetate and lead citrate examined under a transmission electron microscope [JEOL 100CX, JEOL; Tokyo, Japan).

\section{Results}

\section{Immunohistochemistry}

A large number of fluorescent spots which had reacted positively for anti-CX26 and CX32 antibody were observed in endpieces in the rat PGs (Figs. 1, 2). In contrast, only a few CX43 spots were recognizable (Fig. 3). At higher magnification, punctate decoration of CX26 and 32 was detected within the endpieces, consistent with the lateral borders of the endpiece secretory cells (Figs. 1, 2, 4). Immunolabeling was absent from the luminal and basal borders of the endpiece cells. However, CX43-spots were observed around intercalated ducts (Fig. 5). No positive spots for any of the three types CXs were found between ductal cells (Figs. 1, 4, 5). Numerous green CX32 spots stained by FITC indicating CX32 were seen in the endpieces (Fig. 6). Red CX26 spots stained red by rhodamine were observed in the same glandular components (Fig. 7). Reactive spots for both CX26 and CX32 seemed to overlap as indicated by arrows in Figs. 6 and 7 .

The mean number of immunofluorescent spots per $10,000 \mu \mathrm{m}^{2}$ for CX26, CX32 and CX43 are graphically portrayed in Fig. 8. The means for CX26 and CX32 are not significantly different, but both differ significantly from that of CX43 $(p<0.01)$. This analysis confirms the subjective impression gained from Figs. 1-7 that the CX26- and CX32-positive spots are common, while those 

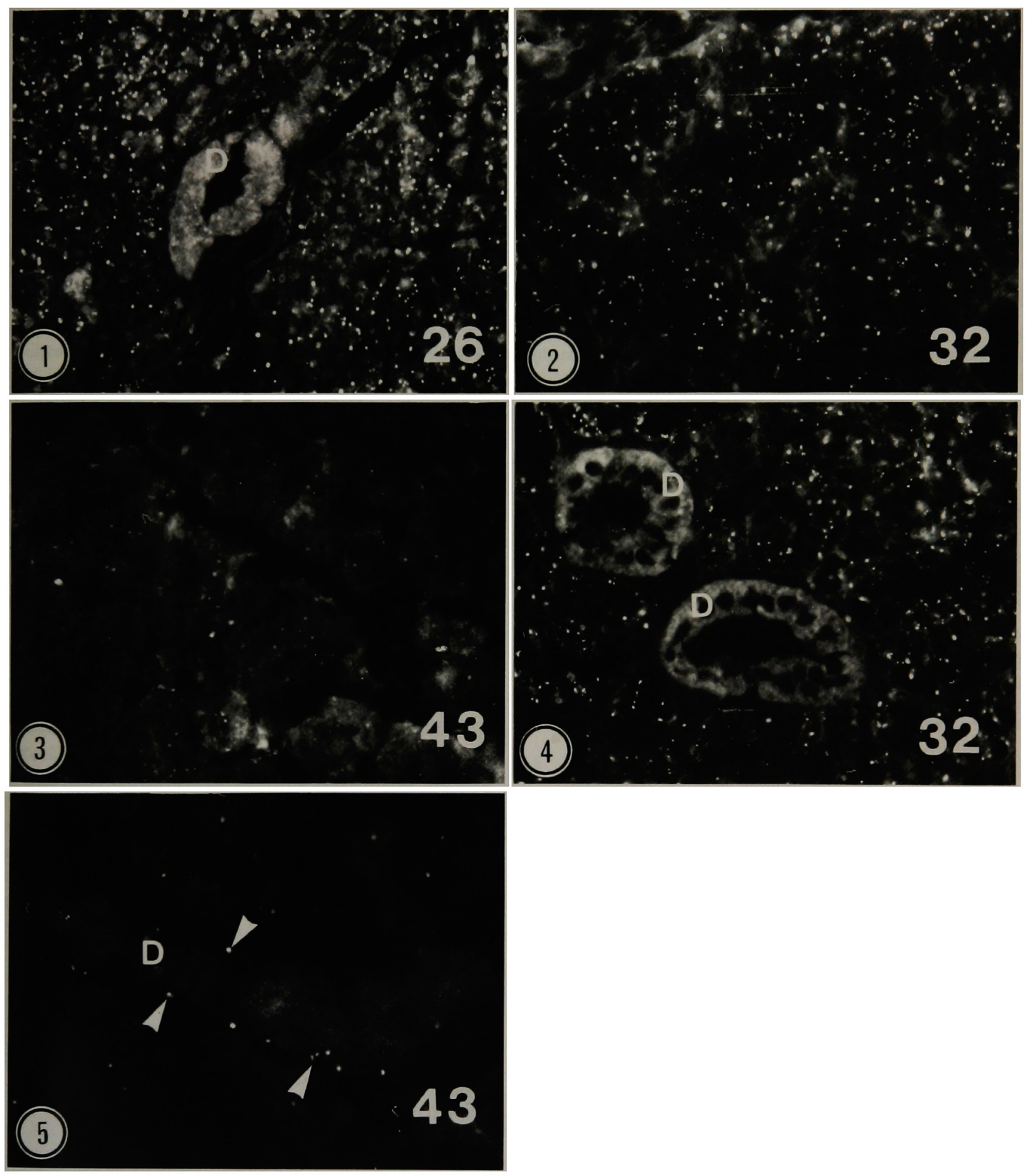

Figs. 1-5. Fluorescent micrographs. Fluorescent spots indicating positive reaction with anti-CX26 (Fig. 1) and 32 (Fig. 2) antibodies are observed in endpieces of rat PGs. In contrast, CX43-reactive spots are rare, and their localization is unclear at low magnification (Fig. 3). At higher magnification, punctate decoration of CX26 and 32 is seen mostly within acini, consistent with the apposed lateral plasma borders of the endpiece secretory cells (CX32; Fig. 4, CX26; data not shown). A few CX43-reactive sites can be detected around an intercalated duct (Fig. 5). No positive spots for any connexin are detected between ductal cells in PGs (Figs. 1, 4, 5). Original magnifications: Figs. 1, 2, $3 \times 280$; Fig. $4 \times 350$; Fig. $5 \times 420$, D: duct. 

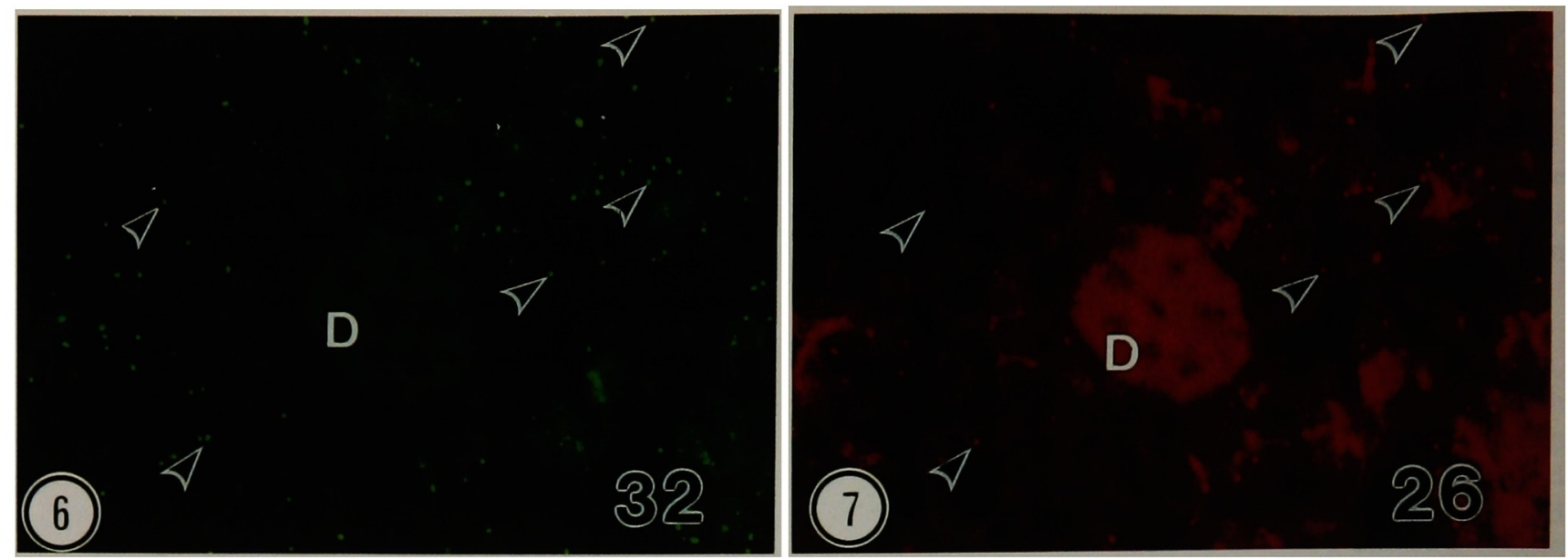

Figs. 6, 7. Fluorescent micrographs. Double-labeling immunofluorescent microscopy reveals that CX32-reactive sites (Fig. 6, FITC; green) correspond to the same sites where CX26 reacted (Fig. 7, rhodamine; red) in rat PGs (arrowheads show the same sites). No positive spots for both CXs are detected between ductal cells. Original magnifications: Figs. 6, 7 × 325; D: duct.

of CX43 are rare.

\section{Immunocytochemistry}

In ultrathin cryosections, intracytoplasmic structures were poorly preserved, because the concentration of the fixative used in this study was lower than usual. However, the plasma membrane was relatively well-preserved. By using the presence of electron-lucent spaces indicating secretory granules or elongated endoplasmic reticulum as markers, it was possible to distinguish endpiece secretory cells from myoepithelial cells in the rat PGs. Immuno-

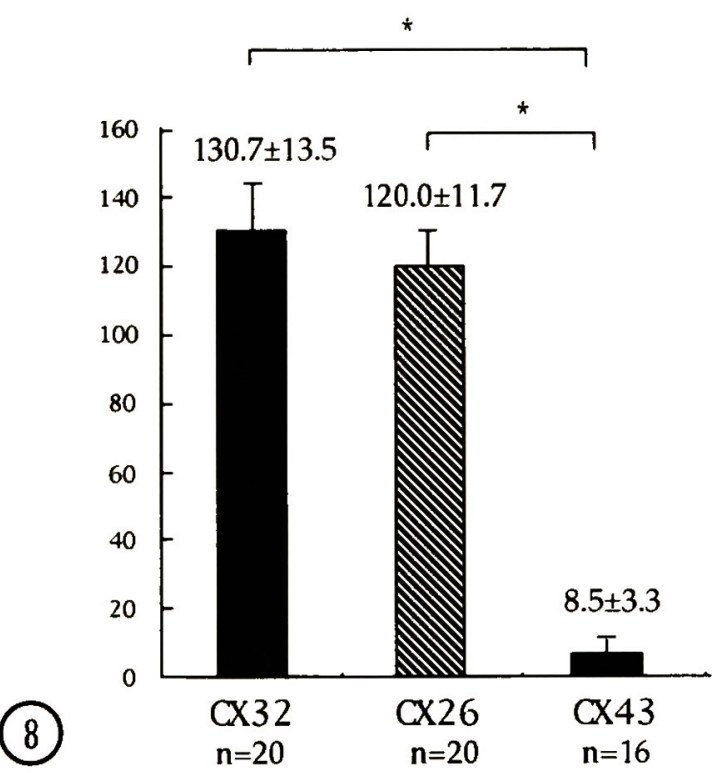

Fig. 8. The mean numbers of positive spots for CXs per 10,000 $\mu \mathrm{m}^{2}$ in PG. CX26-positive spots are most common; in contrast, CX43-reactive spots are rare. There are statistically significant differences between $\mathrm{CX} 26$ and 43 , and between $\mathrm{CX} 32$ and 43 by Mann-Whitney's U-test $(p<0.01)$. labeled particles for CX26 and 32 were observed at GJs between secretory cells of PGs in ultrathin cryosections. In double immuno-electron micrographs, $5 \mathrm{~nm}$ particles indicating CX32 and $10 \mathrm{~nm}$ gold particles revealing CX26 were found on or contiguous to GJs between endpiece cells (Fig. 9). The number of $5 \mathrm{~nm}$ gold particles was relatively greater than that of $10 \mathrm{~nm}$ particles. No orderly distribution of both particles was apparent.

\section{Discussion}

There have been many morphological investigations on GJs in the salivary glands $[18,21,22,25]$. GJs exist between acinar cells, between myoepithelial cells, and also

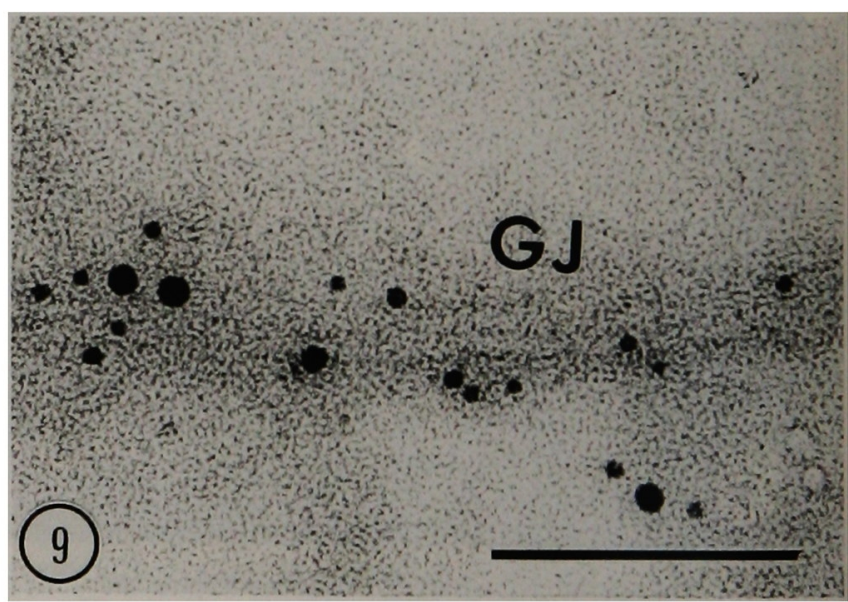

Fig. 9. Electron micrograph. Double immuno-electron microscopy confirming that connexin 32 and 26 are co-localized in the same GJs between secretory cells of PGs in ultrathin cryosections. The gold particles are located at closely apposed plasma membranes of endpiece cells. Magnifications: $\times 300,000 ; \mathrm{Bar}=0.1 \mu \mathrm{m}, \mathrm{GJ}$, gap junction; Small $(5 \mathrm{~nm})$ gold particles show CX32-reaction; Large $(10 \mathrm{~nm})$ ones are CX26 localization. 
between acinar cells and myoepithelial cells, but not between ductal cells [21]. On the other hand, some investigators have suggested the presence of GJs in ductal regions [25]. Recently, immunohistochemical analysis has become available for researching localization and distribution of GJ proteins in salivary glands. Hirono et al. (1995) reported that $21 \mathrm{kDa}-\mathrm{GJ}$ protein was localized at intercalated ducts in rat PGs and submandibular glands, but not observed in sublingual glands [10]. Our immunohistochemical results contradict these earlier studies in that we found no positive spots for any CX between ductal cells. Our finding is supported by the results of conventional electron microscopic and freeze-fracturing studies by Nagato and Tandler (1986) [18] and Shimono et al. (1980) [21] who found no GJs between ductal cells.

There are a few previous immunohistochemical studies of CX expression in the salivary glands, that showed CX26, CX32 and CX43 are present in the rat salivary glands $[10,13,16,17]$. We previously demonstrated $C X$ localization in the rat submandibular and sublingual glands [17]. The localization, distribution, and frequency of CX32 in submandibular and sublingual glands did not differ significantly. Kuraoka et al. (1994) indicated that CX26 and 32 were co-localized by double immunofluorescence in the same GJs in rat PGs; their data agree with our results [13]. However, our observations at the optical microscopic level might allow for varying interpretations. Therefore, we investigated the detailed localization of CX26 and 32 using immuno-electron microscopy to confirm whether both CXs were present in the same GJs. We were able to demonstrate the co-localization of both CXs in the same GJ between endpiece cells. These findings suggest that both CX26 and 32 are closely associated with secretory function in rat PGs. It is still not completely clear why CX26 and 32 are present between endpiece cells. One possibility is that the co-existence of both CX26 and 32 may be associated with phosphorylation. It has been surmised that CX32 has several phosphorylation sites, whereas CX26 is devoid of them. Further, Barrio et al. (1991) reported that CX26 exhibited different properties compared to CX32, and that the combination of CX26 and 32 resulted in differential control of the permeability of GJs [1]. Therefore, it is possible that phosphorylation of these CXs plays an important role in GJ permeability.

Our results also have shown that immunolabeling for CX26 and 32 was strong between secretory cells and that CX43 was very rare in rat PGs. Muramatsu et al. (1996) have demonstrated immunocytochemically that CX43 is abundant between GJs of myoepithelial cells in rat sublingual glands [17]. Comparing the results in this study with those in our previous study, the frequency of CX43 in PGs was definitely lower than that in both submandibular and sublingual glands. It is well established that myoepithelial cells invest only the intercalated ducts in the mature rat PG, although their processes often extend onto adjacent portions of acini and striated ducts $[7,19]$. Thus, the observed localization of CX43 around the intercalated ducts but not acini in rat PG suggests that CX43 marking GJs between myoepithelial cells processes and between these processes and intercalated duct cells.

\section{Acknowledgments}

The authors wish to thank Prof. Y. Shibata and Dr. A. Kuraoka for supplying CX26 antibody, Dr. F. Ueda for supplying CX32 antibody, Dr. Y. Enokiya and Dr. S. Hashimoto for technical assistance in electron microscopy, and Dr. T. Inoue for valuable criticism and discussions on this manuscript. This study was supported, in part, by Oral Health Science Center grant $961 \mathrm{~B} 03$ from Tokyo Dental College.

\section{References}

1. Barrio, L. C., Suchyna, T., Bargiello, T., Xu, L. X., Roginski, R. S., Bennett, M. V. L. and Nicholson, B. J.: Gap junctions formed by connexins 26 and 32 alone and in combination are differently affected by applied voltage. Proc. Natl. Acad. Sci. USA 88; 8410-8414, 1991.

2. Beyer, E. C., Paul, D. L. and Goodenough, D. A.: Connexin 43: A protein from rat heart homologous to a gap junction protein from liver. J. Cell Biol. 105; 2621-2629, 1987.

3. Beyer, E. C., Paul, D. L. and Goodenough, D. A.: Connexin family of gap junction proteins. J. Membr. Biol. 116; 187-194, 1990.

4. Beyer, E. C., Kistler, J., Paul, D. L. and Goodenough, D. A.: Antisera directed against connexin 43 peptides react with a 43 $\mathrm{kD}$ protein localized to gap junctions in myocardium and other tissues. J. Cell Biol. 108; 595-605, 1989.

5. Dewey, M. M. and Barr, L.: A study of the structure and distribution of the nexus. J. Cell Biol. 23; 553-585, 1964.

6. Dunn, J. and Revel, J. P.: Association of gap junctions with endoplasmic reticulum in rat parotid glands. Cell Tissue Res. 238; 589-594, 1984.

7. Garrett, J.R. and Parsons, P. A.: Alkaline phosphatase and myoepithelial cells in the parotid gland of the rat. Histochem. J. 5; 463-471, 1971.

8. Hand, A. R.: Adrenergic and cholinergic nerve terminals in the rat parotid gland. Electron microscopic observations on permanganate-fixed glands. Anat. Rec. 173; 131-140, 1972.

9. Hertzberg, E. L.: A detergent-independent procedure for the isolation of gap junctions from rat liver. J. Biol. Chem. 259; 9936-9943, 1984.

10. Hirono, C., Shiba, Y. and Kanno, Y.: Different localizations of 21 and $27 \mathrm{kDa}$ gap-junction proteins in rat salivary glands. Histochemistry 103; 39-46, 1995.

11. Koike, K., Watanabe, H., Hiroi, M. and Tonosaki, A.: Gap junction of stratum granulosum cells of mouse follicles: Immunohistochemistry and electron microscopy. J. Electron Microsc. 42; 94-106, 1993.

12. Kumar, N. M. and Gilula, N. B.: Cloning and characterization of human and rat liver cDNAs coding for a gap junction protein. J. Cell Biol. 103; 767-776, 1986.

13. Kuraoka, A., Yamanaka, I., Miyahara, A., Shibata, Y. and Uemura, T.: Immunocytochemical studies of major gap junction proteins in rat salivary glands. Eur. Arch. Otorhinolaryngol. 251 (Suppl. 1); S95-99, 1994.

14. Kuraoka, A., Iida, H., Hatae, T., Shibata, Y., Itoh, M. and Kurita, T.: Localization of gap junction proteins, connexin 32 and 26 , in rat and guinea pig liver as revealed by quick-freeze, deep-etch immunoelectron microscopy. J. Histochem. Cyto- 
chem. 41; 971-980, 1993.

15. Loewenstein, W. R.: The cell-to-cell channel of gap junctions. Cell 48; 725-726, 1987.

16. Meda, P., Pepper, M.S., Traub, O., Willecke, K., Gros, D., Beyer, E., Nicholson, B., Paul, D. and Orci, L.: Differential expression of gap junction connexins in endocrine and exocrine glands. Endocrinology 133; 2371-2378, 1993.

17. Muramatsu, T., Hashimoto, S. and Shimono, M.: Differential expression of gap junction protein connexin 32 and 43 in rat submandibular and sublingual glands. J. Histochem. Cytochem. 44; 49-56, 1996.

18. Nagato, T. and Tandler, B.: Gap junctions in rat sublingual gland. Anat. Rec. 214; 71-75, 1986.

19. Nagato, T., Yoshida, H., Yoshida, A. and Uehara, Y.: A scanning electron microscope study of myoepithelial cells in exocrine glands. Cell Tissue Res. 209; 1-10, 1980.

20. Nicholson, B., Dermietzel, R., Teplow, D., Traub, O., Willecke, K. and Revel, J. P.: Two homologous protein components of hepatic gap junctions. Nature 329; 732-734, 1987.
21. Shimono, M., Yamamura, T. and Fumagalli, G.: Intercellular junctions in salivary glands: Freeze-fracture and tracer studies of normal rat sublingual gland. J. Ultrastruct. Res. 72; 286299, 1980.

22. Sugiura, K.: Structure and distribution of intercellular junctions on the rat sublingual gland: A study with freeze-fracture technique, lanthanum impregnation and ruthenium red staining. Shikwa. Gakuho. 78; 809-834, 1978.

23. Takeda, A., Kanoh, M., Shimazu, T. and Takeuchi, N.: Monoclonal antibodies recognizing different epitopes of the 27$k D a$ gap junction protein from rat liver. J. Biochem. 104; 901907, 1988.

24. Tandler, B. and Cohan, R. P.: Ultrastructure of the parotid gland in the little brown bat. Anat. Rec. 210; 491-502, 1984.

25. Young, J. A. and Van Lennep, E. W.: The Morphology of salivary glands, Academic Press, London/New York, 1978.

26. Zhang, J. T. and Nicholson, B. J.: Sequence and tissue distribution of a second protein of hepatic gap junctions, CX26, as deduced from its cDNA. J. Cell Biol. 109; 3391-3401, 1989. 